\title{
The preliminary clinical observation and analysis of childbearing- age women with a history of iodine-131 treatment for Graves' disease
}

\author{
Liang Guan ${ }^{1,2}$, Gang Chen ${ }^{1,2}$, Jiali Zhang ${ }^{3,4,5}$, Ling Wang ${ }^{3,4,5, *}$ \\ ' Department of Nuclear Medicine, Ruijin Hospital, School of Medicine, Shanghai Jiaotong University, Shanghai, China; \\ ${ }^{2}$ Department of Nuclear Medicine, Ruijin Hospital North, School of Medicine, Shanghai Jiaotong University, Shanghai, China; \\ ${ }^{3}$ Laboratory for Reproductive Immunology, Hospital \& Institute of Obstetrics and Gynecology, IBS, Shanghai Medical College, \\ Fudan University, Shanghai, China; \\ ${ }^{4}$ The Academy of Intergrative Medicine of Fudan University; \\ ${ }^{5}$ Shanghai Key Laboratory of Female Reproductive Endocrine Related Diseases, Shanghai, China.
}

\begin{abstract}
Summary Whether radioactive iodine treatment of Graves' disease (GD) during pregnancy will increase pregnancy loss and affect fetal development is still a matter of concern. From May 2005 to December 2015, 2,276 childbearing-age women with GD received iodine-131 treatment in our departments and were retrospectively enrolled in our study. When some of them were found to have been pregnant, their thyroid functions were measured every 4 weeks, in addition, thyroid-stimulating hormone (TSH) was measured 6 weeks after delivery. When necessary, levothyroxine or propylthiouracil (PTU) was given in order to control their TSH levels during pregnancy. Finally, 69 pregnant women $(29 \pm 3.5$ years old $)$ and 1346 women who were not pregnant during the follow-up period were enrolled into this study. They were all hyperthyroid before or during pregnancy. Among 69 pregnant women, the administrated amount of iodine-131 was $254.9 \pm 99.9 \mathrm{MBq}$. Fifty patients became subclinically hypothyroid after treatment and were administrated levothyroxine $(55 \pm 25 \mu \mathrm{g} / \mathrm{d})$. Seven patients were diagnosed with subclinical hyperthyroidism during pregnancy and they received PTU (25 $\pm 12.5 \mathrm{mg} / \mathrm{d}$ ). Twelve patients with normal thyroid function were also clinically followed. Among 69 women, 63 had a single birth, 3 had dizygotic twins, 2 had two pregnancies and 1 had a single twin birth. Sixty five babies were born full-term, while 9 were premature (4 \pm 1 weeks early) with birth weight $3.2 \pm 0.5 \mathrm{~kg}$. Six new born babies were considered to be low birth weight infants $(<2.5 \mathrm{~kg})$ while 5 were high birth weight $(>4 \mathrm{~kg})$, but the weights of all the infants were within the normal range. During the period of observation to December 2015, all the infants were found to grow and develop normally. Among 1346 women who were not pregnant were in the further follow-up. Our study found no detrimental effects of the iodine-131 treatment in the pregnant women or their offspring so far.
\end{abstract}

Keywords: Graves' disease, pregnancy, iodine-131

\section{Introduction}

Graves' disease (GD) is one of the most common causes of hyperthyroidism worldwide, especially in iodine-

Released online in J-STAGE as advance publication May 13, 2016.

*Address correspondence to:

Dr. Ling Wang, Obstetrics \& Gynecology Hospital of Fudan University,413 Zhaozhou Road, Shanghai 200011, China.

E-mail: Dr.wangling@fudan.edu.cn sufficient areas. GD accounts for nearly $90 \%$ of all cases and the incidence rate is about 1 in 1,000 per year (1). In China, the prevalence of hyperthyroidism is about $3 \%$, with $88 \%$ to $90 \%$ being caused by GD (2). The treatment strategy varies around the world. In the United States and Europe, radioactive iodine-131 treatment is the first therapeutic choice and is widely accepted by physicians and patients (3). After more than 60 years of experience with iodine-131, it has been shown to be an inexpensive, safe, and effective treatment for hyperthyroidism $(4,5)$. However, despite a high rate of recurrence, anti-thyroid 
drugs (ATDs) such as methimazole and propylthiouracil (PTU) were still used as the preferred treatment for GD in China and other countries in Asia. The main concern among general practitioners is iodine-131 induced hypothyroidism, because many rural patients do not comply with lifelong regular levothyroxine (L-T4) replacement (2). Nevertheless, changing economic factors and high relapse rates observed after discontinuation of ATD treatment, the use of iodine-131 has dramatically increased.

Although iodine-131 therapy is generally well tolerated, potential side effects may occur, such as radiation-induced thyroiditis, sialadenitis, bone marrow depression, pulmonary fibrosis, and rarely induction of a second primary malignancy (6-8). Besides, transient or chronic hypospermia can be detected $(9,10)$, as well as possible early onset of menopause (11) and menstrual cycle abnormalities (12). The mentioned severe side effects were all observed in those who receive high dose iodine-131 treatment in thyroid cancer instead of the lower doses used in the treatment of GD. Considering the much lower dose of iondine-131 administrated in GD than in cancer, we investigated whether iodine-131 treatment in GD would increase pregnancy loss and alter fetal development. Here, we aimed to investigate the pregnancy outcomes of childbearing-age women with GD who inadvertently received iodine-131 treatment in our hospitals.

\section{Materials and Methods}

\subsection{Patients}

From May 2005 to December 2015, 2,276 childbearingage (from 20 to 40 years old ) women with GD received iodine-131 treatment in Ruijin Hospital and Ruijin Hospital North (Shanghai Jiaotong University, School of Medicine, Shanghai, China) and were retrospectively enrolled. We excluded patients who delivered before iodine-131 treatment, and were unwilling to participate or failed to appear for follow-up for this study. Eventually, we enrolled 69 pregnant women and 1346 women who were not pregnant during the whole treatment and follow-up period.

\subsection{Hyperthyroidism Treatment}

The diagnoses of hyperthyroidism were based on serum free triiodothyronine (FT3), free thyroxine (FT4) and thyroid-stimulating hormone (TSH) levels, 24 hours thyroid radioactive iodine uptake (RAIU). Thyroid weight was based on color Doppler ultrasonography inspection and palpation. Accordingly, nuclear medicine physicians calculated and checked the required activity of iodine-131 (Shanghai Anshengkexing Pharmaceutical Co. Ltd., Shanghai, China) for individual patients. When necessary, repeated treatments were performed as needed in other studies (13). Before iodine-131 treatment, women of childbearing age underwent routine detection of serum $\beta-\mathrm{HCG}$, which was an endocrine indicator of pregnancy. If the pregnant woman was found to have severe hyperthyroidism, she was advised to interrupt the pregnancy and receive treatment two months later. If the woman became pregnant within 6 months after iodine-131 treatment, and her hyperthyroid symptoms persisted unabated, the patient was recommended for therapeutic abortion in accord with the maternal condition and fetal development status.

Patients were informed of radiation safety guidelines before iodine-131 treatment, and they all agreed and signed informed consents.

\subsection{Follow-up}

The follow-up was divided into two parts. One was regular follow-up after iodine-131 treatment for all women enrolled in our study, the other was specific for pregnancy and birth follow-up after iodine-131 for 69 pregnant women. Regular follow-up observation after iodine-131 treatment was conducted at 1 month, 3 months, 6 months and 1 year after iodine-131 treatment. Measurements of serum FT3, FT4 and TSH levels of the treated patients were performed to indicate thyroid functional restoration and measurement of the volume of thyroid was conducted at the same time. During the follow-up, if women had significantly increased FT3 or FT4, and goiter (over I degree goiter) after treatment, they had another iodine-131 treatment (3 6 months after previous treatment) as an outpatient. If women had slightly increased FT3, FT4 or TSH without goiter, they received moderate anti-thyroid drugs (ATDs) or levothyroxine (L-T4), or continued observation as an ordinary outpatient. As for 69 pregnant women, they first had serum $\beta$ - Human chorionic gonadotropin (hCG) and mode-B ultrasonography for baby at 4 to 8 gestational weeks to confirm pregnancy. The thyroid functions of pregnant women were monitored every 4 weeks. The thyroid function was measured at 6 months postpartum, and the height, weight and intelligence development of babies were also monitored at the same time.

\subsection{Pregnancy management}

Management of thyroid function during pregnancy: $i$ ) According to the follow-up measurements of thyroid function and related hormones at 1 months, 3 months, 6 months and 1 year after iodine-131 treatment, the treated patients were classified in three thyroid function states: euthyroid, subclinical hyperthyroid and subclinical hypothyroid; ii) The treated women patients were administered adjustable doses of L-T4 as needed, depending on the serum TSH level; iii) The treated 
women were recommended to avoid pregnancy until more than 6 months after iodine-131 treatment. L-T4 for hypothyroid patients was administered and PTU was prescribed for hyperthyroid patients to control the serum TSH level below $2.5 \mathrm{mU} / \mathrm{L}$. The objective serum $\mathrm{TSH}$ level in pregnancy ranges from 0.1 to $2.5 \mathrm{mU} / \mathrm{L}$ in early stage, from 0.2 to $3.0 \mathrm{mU} / \mathrm{L}$ in middle stage and from 0.3 to $3.0 \mathrm{mU} / \mathrm{L}$ in late stage.

Those pregnant women enrolled in our study underwent antenatal care regularly in order to monitor the normal growth and development status of the fetuses, and healthy condition of mothers, mainly including fetal malformation screening, periodic mode-B ultrasonography, and amniotic cell karyotype analysis would be done if it was necessary to further confirm numerical and structural fetal chromosomal aberrations.

\subsection{Statistical analysis}

Statistical analysis was carried out using software package SPSS17.0, and statistically significant differences were assessed by one-way ANOVA followed by Tukey's test. A p value of less than 0.05 was considered to be statistically significant. All descriptive data was reported as median \pm standard deviation $(\overline{\mathrm{x}} \pm \mathrm{s})$.

\section{Results}

Among 2,276 childbearing-age women with GD who received iodine-131 treatment during May 2005 to December 2015, 769 women delivered before iodine-131 treatment, 92 women were unwilling to participate or failed to appear for follow-up for this study for individual reasons except for healthy problems. The reasons we failed to follow-up were mainly that patients came from all around China often went back to their hometown after treatment, and thus it was hard to follow when they changed their contact information. It was also hard to look for their information in researching birth registries in the region because it didn't cover all distant places around China. Those women were excluded from our study. Finally, 1,346 women did not become pregnant after therapy and 69 successfully pregnant women were enrolled for further analysis. They were all hyperthyroid before pregnancy, and received iodine-131 treatment in our hospital. Some patients received treatment several times, and the earliest treatment started from May 3nd, 2005. The circulating thyroid hormone hormones levels were measured by chemiluminescent immunoassay, and the results showed the FT3 levels of these patients before treatment were all above $5.7 \mathrm{pmol} / \mathrm{L}$ (reference value range: $2.63-5.70 \mathrm{pmol} / \mathrm{L})$, FT4 levels were all above $19 \mathrm{pmol} / \mathrm{L}$ (reference value range: 9.01-19.04 pmol/L), and TSH levels were less than $0.3 \mathrm{mU} /$
L (reference value range: 0.35-4.94 mU/L). Before treatment, each individual's 24 hour thyroid RAIU was more than $50 \%$. Accordingly, the nuclear medicine physicians calculated and checked the required activity of iodine-131 for individuals, and considered much concern about hypothyroidism after treatment. The administered patient-specific doses were conservatively among low and medium dosage, most ranged from 111 to $333 \mathrm{MBq}$ (average $222 \mathrm{MBq}$ ).

\subsection{Analysis of the 69 pregnant women}

The nuclear medicine physicians calculated and checked the required activity of iodine-131 for individuals, 254.9 \pm 99.9 MBq (range from 92.5-740 MBq) of iodine-131 (Table 1, Figure 1A). Before pregnancy, 55 patients received one single dosage, 11 patients received two treatments, 1 patient was treated three times (No.67) and the other 2 had four treatments (No. 68 and No. 69). The interval between first and second iodine-131 treatment was $7 \pm 6$ months, interval between second and third iodine-131 treatment was $6 \pm 2$ months, and interval between second and third iodine-131treatment was $6 \pm 1$ months (Figure 1B).

On the other hand, the interval between pregnancy and iodine-131 treatment was $22 \pm 16$ months (range from 4-76 months) in all 69 participants. Because an increased risk of miscarriage, fetal or neonatal death is correlated with higher maternal TSH levels in pregnancy (14), the mothers' serum TSH levels should be manipulated to lower levels before they become pregnant. After iodine-131 treatment, 50 women patients were subclinically hypothyroid, and they needed L-T4 to control TSH and circulating thyroid hormones to maintain normal thyroid function. The administration doses were $55 \pm 25 \mu \mathrm{g} / \mathrm{d}$. Pregnant women were administered adjusted doses of L-T4 depending on TSH levels measured every 4 weeks to control TSH levels below $2.5 \mathrm{mU} / \mathrm{L}$. The administered doses during pregnancy were changed from $12.5-25 \mu \mathrm{g} / \mathrm{d}$. 7 patients were subclinically hyperthyroid after iodine-131 treatment, and their administered PTU doses were 25 $\pm 12.5 \mathrm{mg} / \mathrm{d}$. While the other 12 euthyroid patients had normal thyroid function test results.

A retrospective analysis showed that the morbidity of birth disorders in the region was $1.06 \%$ in the recent year and congenital heart disease, multi finger (toe), hypospadias, cleft lip, and palate and deformity of external ear were the 5 top birth defects. Compared to infants born with no birth defects, male, low birth weight, twins and multiple births were statistically higher in infants (15). Complication of labor and pregnancy, pregnant infection, fetal growth restriction (FGR), birth disorders can be the first five reasons related to stillbirth (16). In the 8 th and 16 th gestational weeks, the 69 pregnant women received mode-B ultrasonography studies to detect their fetal 
Table 1. Iodine-131 treatment and pregnancy outcomes of 69 cases of hyperthyroid women patients (until 12-30-2015)

\begin{tabular}{|c|c|c|c|c|c|c|c|c|}
\hline \multirow{2}{*}{$\begin{array}{l}\text { Treatment } \\
\text { times }\end{array}$} & \multirow{2}{*}{ No. } & \multirow{2}{*}{$\begin{array}{c}\text { I-131 dose } \\
(\mathrm{MBq})\end{array}$} & \multicolumn{2}{|c|}{ Thyroid function management } & \multirow{2}{*}{$\begin{array}{l}\text { Interval between pregnancy } \\
\text { and treatment (month) }\end{array}$} & \multirow{2}{*}{$\begin{array}{l}\text { Infant age } \\
\text { (years) }\end{array}$} & \multirow{2}{*}{$\begin{array}{l}\text { Infant gender } \\
(\mathrm{M} / \mathrm{F})\end{array}$} & \multirow{2}{*}{$\begin{array}{l}\text { Birth-weight } \\
(\mathrm{kg})\end{array}$} \\
\hline & & & $\mathrm{L}-\mathrm{T} 4(\mu \mathrm{g})$ & PTU (mg) & & & & \\
\hline \multirow[t]{55}{*}{1} & 1 & 111 & & & 16 & 2.7 & $\mathrm{~F}$ & 3 \\
\hline & 2 & 111 & & & 9 & 3.0 & $\mathrm{~F}$ & 3 \\
\hline & 3 & 111 & 75 & & 5 & 4.1 & M & 3.8 \\
\hline & 4 & 111 & 50 & & 33 & 2.6 & $\mathrm{M}$ & 3.8 \\
\hline & 5 & 111 & 62.5 & & 30 & 1.9 & $\mathrm{~F}$ & 3.5 \\
\hline & 6 & 111 & 50 & & 15 & 1.2 & M & 3.3 \\
\hline & 7 & 111 & 125 & & 5 & 1.1 & M & 3.3 \\
\hline & 8 & 111 & & 25 & 11 & 1.4 & M & 4.1 \\
\hline & 9 & 129.5 & 50 & & 9 & 5.6 & $\mathrm{M}$ & 3.4 \\
\hline & 10 & 129.5 & 25 & & 41 & 2.7 & $\mathrm{~F}$ & 3.5 \\
\hline & 11 & 148 & & & 13 & 7.4 & $\mathrm{~F}$ & 2.6 \\
\hline & 12 & 148 & 25 & & 8 & 0.2 & $\mathrm{~F}$ & 3.05 \\
\hline & 13 & 162.8 & 100 & & 15 & 4.7 & $\mathrm{~F}$ & 2.85 \\
\hline & 14 & 185 & & & 22 & 1.1 & $\mathrm{M}$ & 3.9 \\
\hline & 15 & 185 & 25 & & 12 & 5.9 & $\mathrm{M}$ & 3.4 \\
\hline & 16 & 185 & 75 & & 14 & 5.4 & $\mathrm{~F}$ & 3.3 \\
\hline & 17 & 185 & 25 & & 38 & 0.6 & $\mathrm{~F}$ & 4 \\
\hline & 18 & 203.5 & 25 & & 16 & 3.9 & $\mathrm{M}$ & 3.05 \\
\hline & 19 & 203.5 & 50 & & 31 & 3 & M & 2.8 \\
\hline & 20 & 203.5 & 37.5 & & 69 & 1.3 & $\mathrm{~F}$ & 3.05 \\
\hline & 21 & 214.6 & & & 25 & 4.1 & $\mathrm{~F}$ & 3.45 \\
\hline & 22 & 222 & 100 & & 13 & 5.9 & M & 3.2 \\
\hline & 23 & 222 & 75 & & 29 & 4.5 & $\mathrm{~F}$ & 2.85 \\
\hline & 24 & 222 & 37.5 & & 8 & 2.2 & $\mathrm{~F}$ & 3.3 \\
\hline & 25 & 222 & 25 & & 49 & 1.4 & $\mathrm{~F}$ & 4.01 \\
\hline & 26 & 222 & 50 & & 48 & 1.2 & M & 3.5 \\
\hline & 27 & 222 & 12.5 & & 22 & 1.2 & $\mathrm{~F}$ & 2.45 \\
\hline & 28 & 222 & & 25 & 8 & 3.0 & M & 2.75 \\
\hline & 29 & 240.5 & 50 & & 10 & 6.0 & M & 2.85 \\
\hline & 30 & 240.5 & 50 & & 16 & 3 & $\mathrm{M}$ & 3.3 \\
\hline & 31 & 259 & & & 7 & 4.9 & M & 3.5 \\
\hline & 32 & 259 & 50 & & 21 & 5 & $\mathrm{M}$ & 3.3 \\
\hline & 33 & 259 & 62.5 & & 32 & 2.1 & M & 3.1 \\
\hline & 34 & 259 & 50 & & 53 & 1.8 & M & 3.3 \\
\hline & 35 & 259 & 50 & & 11 & 1.7 & M & 2.8 \\
\hline & 36 & 259 & 75 & & 35 & $2 / 2$ & MT:M/M & $2.5 / 2.5$ \\
\hline & 37 & 259 & 75 & & 10 & $7.4 / 7.4$ & DT:M/F & $3 / 2.9$ \\
\hline & 38 & 259 & 50 & & 75 & 0.7 & $\mathrm{~F}$ & 3.5 \\
\hline & 39 & 259 & & 12.5 & 6 & 4.2 & $\mathrm{M}$ & 4.2 \\
\hline & 40 & 259 & & 25 & 14 & 0.8 & $\mathrm{~F}$ & 3.3 \\
\hline & 41 & 277.5 & 75 & & 34 & 3.0 & $\mathrm{~F}$ & 2.75 \\
\hline & 42 & 277.5 & 100 & & 32 & 2.2 & $\mathrm{~F}$ & 2.3 \\
\hline & 43 & 277.5 & 50 & & 22 & $3.7 / 3.7$ & DT:F/M & $2.2 / 2.3$ \\
\hline & 44 & 296 & & & 55 & 1.7 & M & 3.3 \\
\hline & 45 & 296 & 50 & & 10 & 6.0 & $\mathrm{~F}$ & 2.8 \\
\hline & 46 & 296 & 50 & & 16 & 5.1 & $\mathrm{M}$ & 3.35 \\
\hline & 47 & 296 & 50 & & 13 & 3.1 & M & 3.5 \\
\hline & 48 & 296 & 50 & & 35 & 0.4 & $\mathrm{~F}$ & 3.35 \\
\hline & 49 & 333 & & & 19 & 3.2 & $\mathrm{~F}$ & 2.4 \\
\hline & 50 & 333 & 25 & & 10 & 6.7 & $\mathrm{~F}$ & 3.6 \\
\hline & 51 & 333 & 100 & & 36 & 3.8 & $\mathrm{M}$ & 3.9 \\
\hline & 52 & 333 & 50 & & 11 & 3.6 & $\mathrm{M}$ & 4.25 \\
\hline & 53 & 333 & 100 & & 18 & 2.7 & $\mathrm{~F}$ & 3 \\
\hline & 54 & 351.5 & 50 & & 11 & 5.9 & M & 3.6 \\
\hline & 55 & 351.5 & 50 & & 13 & 3.3 & $\mathrm{~F}$ & 2.5 \\
\hline 2 & 56 & $185 / 222$ & 50 & & 28 & 4.3 & $\mathrm{~F}$ & 2.9 \\
\hline & 57 & $259 / 166.5$ & & & 20 & 1.5 & M & 3.6 \\
\hline & 58 & $259 / 203.5$ & 3.75 & & $12 / 31$ & $4.8 / 3.2$ & $\mathrm{~F} / \mathrm{M}$ & $3 / 3$ \\
\hline & 59 & $259 / 222$ & & & 14 & 6 & $\mathrm{~F}$ & 3.5 \\
\hline & 60 & $259 / 222$ & 25 & & 10 & 4.4 & M & 3.5 \\
\hline & 61 & $259 / 92.5$ & & & 11 & 0.4 & $\mathrm{~F}$ & 3 \\
\hline & 62 & $277.5 / 277.5$ & & 25 & 11 & 4.2 & $\mathrm{M}$ & 3.25 \\
\hline & 63 & $296 / 240.5$ & 50 & & 14 & 3.8 & $\mathrm{~F}$ & 3.25 \\
\hline & 64 & $314.5 / 203.5$ & 50 & & 10 & 4.5 & $\mathrm{~F}$ & 3.2 \\
\hline & 65 & $333 / 370$ & & 12.5 & 7 & 3.7 & $\mathrm{~F}$ & 3.9 \\
\hline & 66 & $481 / 296$ & $87.5 / 85$ & & $7 / 64$ & $5.8 / 1$ & $\mathrm{M} / \mathrm{M}$ & $2.7 / 3.25$ \\
\hline 3 & 67 & $259 / 296 / 259$ & 100 & & 4 & $5.1 / 5.1$ & $\mathrm{DT}: \mathrm{M} / \mathrm{F}$ & $2.5 / 2.6$ \\
\hline 4 & 68 & $333 / 370 / 370 / 203.5$ & & 50 & 14 & 2.1 & $\mathrm{~F}$ & 3.3 \\
\hline & 69 & $333 / 555 / 740 / 370$ & & & 6 & 4.7 & $\mathrm{M}$ & 2.35 \\
\hline
\end{tabular}

Abbreviation: L-T4, levo thyroxine; PTU, propylthiouracil; M, male; F, female; MT, monozygotic twins; DT, dizygotic twin. 
A

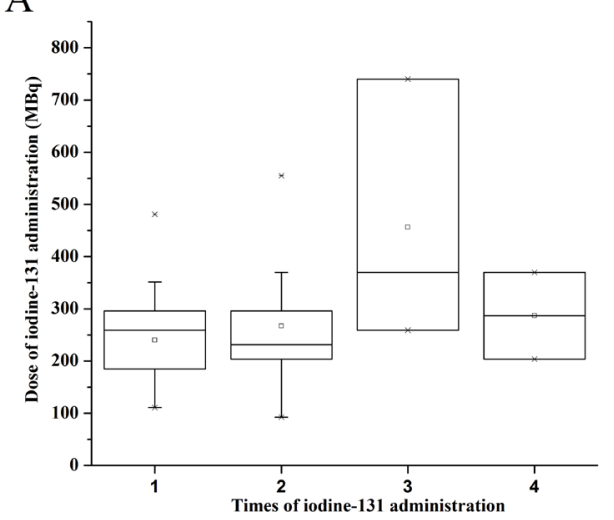

B

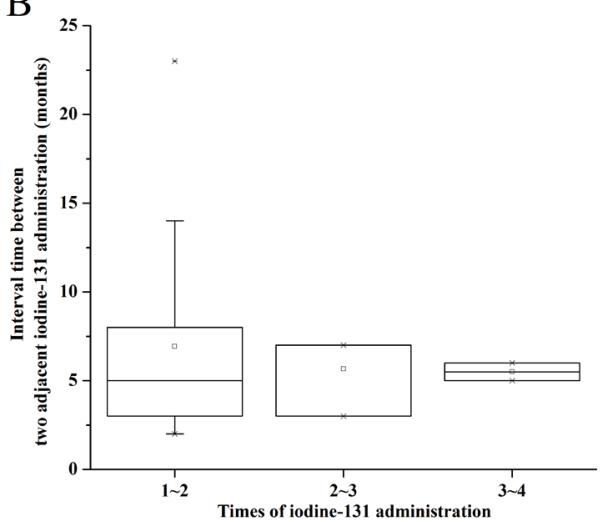

Figure 1. Administration of Iodine-131 in 69 pregnant women (till 2015-12-30). (A) 69 pregnant women with hyperthyroid were administrated iodine-131 at different times, the administered amount was $242.8 \pm 79.5 \mathrm{MBq}$ in all 69 women for the first time, 266.9 $\pm 111.4 \mathrm{MBq}$ in 14 women for the second time, $456.3 \pm 205.6 \mathrm{MBq}$ in 3 women for the third time, and $286.8 \pm 117.7 \mathrm{MBq}$ in 2 women for the fourth time. (B) Among 69 pregnant women, 14 women had a second administration, the interval time between first and second time was $7 \pm 6$ months, 3 women had a third administration, the interval time between second and third time was $6 \pm 2$ months, 2 women had a fourth administration, the interval time between third and fourth time was $6 \pm 1$ months. Abbreviation: $1 \sim 2$, between the first and second iodine-131 administration; 2 3, between the second and third iodine-131 administration; 3 4, between the third and forth iodine-131 administration.

development stage. The inspections showed normal growth and development status of the fetuses. The predictive analysis of prenatal screening in the 16 th gestational week indicated the mothers were at low risk for fetuses with Down's syndrome. Two of these mothers received amniotic cell karyotype analysis in the 20th gestational week to diagnose whether their fetus' chromosomes were indicative of a malformation abnormality, and the results showed no structural change in these cases. Fetal quickening, heart monitoring and mode-B ultrasonography inspections were performed once every 4 weeks after the 24th gestational week to monitor the fetuses developmental status, and to assess whether the fetuses were all in normal condition. One treated patient became pregnant 4th months after iodine-131 treatment (No.67), and mode-B ultrasonography inspection showed the mother conceived dizygotic twins. All inspection parameters of both twins remained normal during pregnancy. The treating physicians discussed in detail and deliberatively reached an agreement to continue the pregnancy with approval of the patient's family.

Among these 69 pregnant patients with successful childbirth, 63 mothers had singleton pregnancies, and 3 had dizygotic twin pregnancies (No. 37, 43 and 67), and among 2 two singleton pregnancies, one successively (No. 66) gave birth to two baby boys, while the other (No. 58) had a baby girl and a baby boy, and 1 had monozygotic twins (No. 36) with two identical baby boys.

The sex ratio of 75 newborn infants was 41 boys $v s$. 34 girls (Figure 2). In all 75 babies, 65 babies were fullterm birth while only 9 were premature $(4 \pm 1$ weeks early). Their birth weight was $3.2 \pm 0.5 \mathrm{~kg} ; 6$ newbirth babies (No. 27, 42, 43, 49,69) were considered to be low birth weight infants $(<2.5 \mathrm{~kg})$ while the other

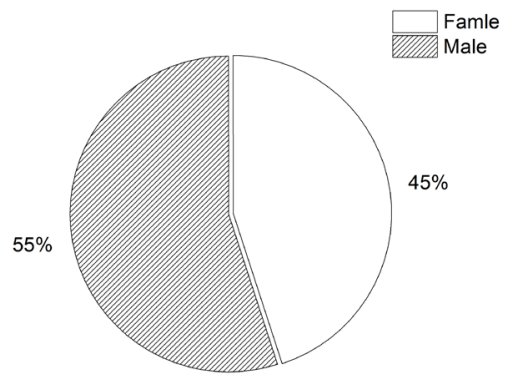

Figure 2. Birth sex ratio of 75 newborn infants. 69 pregnant patients has 75 babies with successful childbirth, the sex ratio of 75 newborn infants was 41 boys $v s .34$ girls. The male proportion was $55 \%$, and the female proportion was $45 \%$.

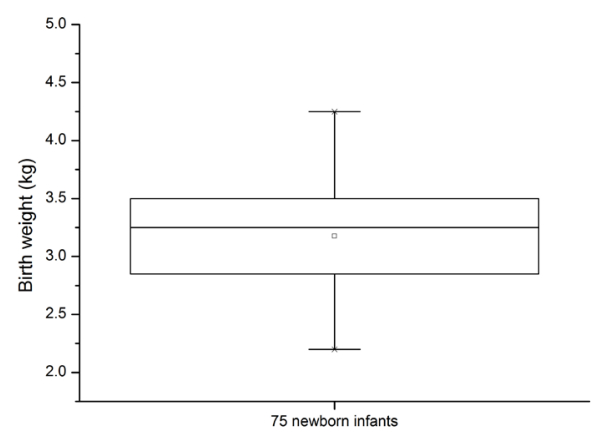

Figure 3. Birth weight of $\mathbf{7 5}$ newborn infants. 69 pregnant patients has 75 babies with successful childbirth, the birth weight of 75 newborn infants was $3.2 \pm 0.5 \mathrm{~kg}$.

5 babies' (No. 8, 17, 25, 39, 52) were high birth weight (>4 kg) (Figure 3).

Of 75 newborn infants, screening for evidence of neonatal diseases, done by analysis of blood samples collected from their heels, showed normal blood physiological and biochemical indices and TSH levels $(0-10 \mathrm{mU} / \mathrm{L})$ in the normal range.

To date, the infants of iodine-131-treated mothers show 

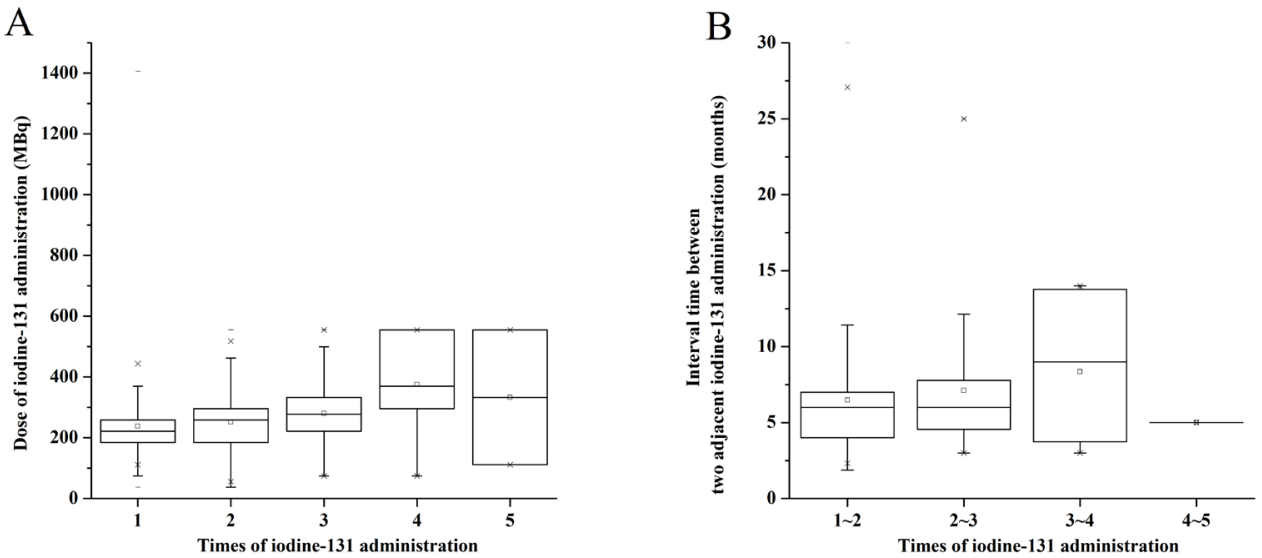

Figure 4 Administration of Iodine-131 in 1346 women with Grave's disease (until 12-30- 2015). (A) 1346 hyperthyroid women were administrated iodine-131 at different times, the administered amount was $237.7 \pm 87.3 \mathrm{MBq}$ in all 1346 women for the first time, $251.83 \pm 89.82 \mathrm{MBq}$ in 289 women for the second time, $280.0 \pm 110.2 \mathrm{MBq}$ in 44 women for the third time, $375.3 \pm 167.4$ $\mathrm{MBq}$ in 7 women for the fourth time, and $333.0 \pm 314.0 \mathrm{MBq}$ in 2 women for the fifth time. (B) Among 1346 pregnant women, 289 women had a second administration, the interval time between first and second time was $6.5 \pm 3.9$ months, 44 women had a third administration, the interval time between second and third time was $7.1 \pm 4.6$ months, 7 women had a forth administration, the interval time between third and fourth time was $8.3 \pm 4.6$ months, 2 women had a fifth administration, the interval time between fourth and fifth time was $5.0 \pm 0$ months.

Table 2. Thyroid function after iodine-131 treatment and pregnancy outcomes of 1346 women with Grave's disease (until 12-30-2015)

\begin{tabular}{lccl}
\hline Items & $\begin{array}{c}\text { Percent of different } \\
\text { thyroid function states }\end{array}$ & $\begin{array}{c}\text { Number of women } \\
\text { under pregnancy }\end{array}$ & Pregnancy outcome \\
\hline Subclinically hypothyroid & $70 \%$ & 3 & 2 had full-term delivery and neonatal death, 2 chose to take PTU to \\
Subclinically hyperthyroid & $20 \%$ & 1 & control the hyperthyroidism and put off the iodine-131 treatment. \\
Euthyroid & $10 \%$ & 1 & - \\
\hline
\end{tabular}

the same developmental progression as do the children of untreated euthyroid mothers with respect to when they sit, crawl, stand, walk, run and talk. The oldest child is now 7.4 years old, and this child's thyroid function, developmental status and intelligence does not show any difference compared to children of the same age. One premature infant of low birth-weight is now 4.7 years old, and his weight at 2 years' old is lighter than children of the same age, but thyroid function and intelligence is the same as his peers.

\subsection{Analysis of the 1346 women who were not pregnant}

The times of iodine-131 treatment in 1346 women who were not pregnant range from 1 to 5 . These 1346 women that were hyperthyroid were administrated iodine-131 at different times, the administered amount was $237.7 \pm 87.3 \mathrm{MBq}$ in all 1346 women for the first time, $251.83 \pm 89.82 \mathrm{MBq}$ in 289 women for the second time, $280.0 \pm 110.2 \mathrm{MBq}$ in 44 women for the third time, $375.3 \pm 167.4 \mathrm{MBq}$ in 7 women for the fourth time, and $333.0 \pm 314.0 \mathrm{MBq}$ in 2 women for the fifth time (Figure 4A). Among 1346 pregnant women, 289 women who had a second administration, the interval time between first and second time was $6.5 \pm$ 3.9 months, 44 women who had a third administration, the interval time between second and third time was 7.1 \pm 4.6 months, 7 women who had a forth administration, the interval time between third and fourth time was 8.3 \pm 4.6 months, 2 women who had a fifth administration, the interval time between fourth and fifth time was $5.0 \pm 0$ (Figure 4B). After iodine-131 treatment, 70\% of women turned to subclinical hypothyroid and administered LT-4 (dose ranges from 50 to $100 \mathrm{mg}$ ), $20 \%$ of women turned to subclinical hyperthyroid and administered PTU (dose ranges from 12.5 to 50 $\mathrm{mg}$ ). While the other $10 \%$ of euthyroid patients had normal thyroid function test results. All patients had no other special side reactions reported so far. Until December, $12^{\text {th }}, 2015,5$ were found pregnant among the 1346 patients (gestational weeks ranged from 6 to 9 months). 3 of them were subclinically hypothyroid and administered LT-4, 1 of them turned to subclinical hyperthyroid and administered PTU and of them 1 had normal thyroid function test results. We had further follow-up and observed 2 of them had full-term delivery, however one of newborn babies died after birth because of congenital heart disease and the other died 3 days after birth because of cerebral hemorrhage. These two babies did not undergo an autopsy. Two patients were found pregnant among the 1346 patients who took the iodine-131 treatment, thus they chose to take PTU to control the hyperthyroidism and put off the iodine-131 treatment until after delivery (Table 2) 


\section{Discussion}

Although iodine-131 treatment of hyperthyroidism has been used in clinical practice for over half a century, data about possible damage to the female gonads after administration for therapeutic purposes are still inconclusive. There are only a few literature reports dealing with this issue and the majority of them deal with high dose treatment for thyroid cancer (17). For women patients, the effects of iodine-131 therapy on gonadal function are a critical consideration because many are of childbearing-age and wish to have healthy children. Female gonads may be affected during iodine-131 therapy from circulating radioiodine in the blood, as well as radiation from the bladder and bowel sequestration during and for a few days post therapy. Therefore, patients are instructed to drink large amounts of fluids and use laxatives if constipated in order to avoid unnecessary radiation to the ovaries (18).

According to the guidelines established by the Society of Nuclear Medicine and Molecular Imaging, female patients who have the potential to be pregnant must always be tested for pregnancy using a urine or serum $\beta$-HCG test before iodine-131 treatment (19). Iodine-131 therapy is absolutely contraindicated in pregnant women and one attempts to avoid inadvertent exposure and this continues to be recommended in the literature. However, Hyer S, et al. (20) demonstrated that exposure to iodine-131 at this very early stage of pregnancy (pre implantation) is unlikely to result in malformations or thyroid dysfunction in surviving embryos; only exposure during thyroidogenesis (from 10 weeks gestation) and organogenesis (from 2 weeks gestation) may result in fetal thyroid ablation, birth defects and in later life, growth retardation and reduction in IQ. Generally speaking, women are advised to delay pregnancy at least 6 months after iodine-131 treatment in China, at which time there should be no risk of them suffering from miscarries or other dangers (21).

Another concern regarding iodine-131 treatment for childbearing-age women in China is the possible result of hypothyroidism. Nevertheless, many experts in western countries consider hypothyroidism after a single dose of iodine-131 a desired outcome of therapy because it avoids frequent office visits and laboratory testing to detect the late onset of hypothyroidism and thereby decreasing the risk of untreated, persistent, or recurrent hyperthyroidism (19). Once identified, use of replacement L-T4 can adjust the patients' thyroid function to the normal range diminishing possible concern regarding hypothyroid induction.

Previous studies in female patients have shown no significant effects of iodine-131 in treating thyroid cancers on fertility rate, birth weight, or congenital anomalies in offspring (22-29). In our study, we have the same experience in treating patients for GD. Among these 26 women patients we observed only successful pregnancy and childbirth, and no birth defects or other malformations were detected.

Of course, the present study has several limitations. The first is the retrospective nature of the study. Another limitation is the relatively small number of patients, which can lead to selection bias. Considering the nonzero frequency of mild and moderate birth disorders in untreated pregnancies, the same fraction would also be expected in the treated group. We haven't seen it yet, mainly due to the relatively small number of patients we have had so far. Our study is still in progress at present, and more patients and cases will be included in the next stage of our study. We will also concentrate on expanding the sample size, and strengthen the followup of treated patients by cooperation of obstetrics with endocrinology. Thus we may be able to get more powerful analysis on birth disorders, still births, normal live births and so on. We expect we can get a more authoritative data statistics in the next few years. For these reasons, we suggest further clinical trials should be undertaken, especially a prospective and multicenter study.

In conclusion, no significant harm to fetuses has been observed on child-bearing age women with GD who received iodine-131 treatment before pregnancy. No significant risk of abnormal fetal development has been observed on pregnant women with GD after a 6-month period of iodine-131 treatment. In order to more firmly establish these conclusions, it will be necessary to study larger numbers of subjects in a prospective multicenter study.

\section{Acknowledgements}

This work was partly supported by the National Natural Science Foundation of China No. 31571196 (to Ling Wang), the Science and Technology Commission of Shanghai Municipality 2015 YIXUEYINGDAO project No. 15401932200 (to Ling Wang), the FY2008 JSPS Postdoctoral Fellowship for Foreign Researchers P08471 (to Ling Wang), the National Natural Science Foundation of China No. 30801502 (to Ling Wang), the Shanghai Pujiang Program No. 11PJ1401900 (to Ling Wang), and the Development Project of Shanghai Peak Disciplines-Integrated Chinese and Western Medicine No.20150407.

\section{References}

1. Vanderpump MP, Tunbridge WM, French JM, Appleton D, Bates D, Clark F, Grimley Evans J, Hasan DM, Rodgers $\mathrm{H}$, Tunbridge F, Young ET. The incidence of thyroid disorders in the community: A twenty-year follow-up of the Whickham Survey. Clin Endocrinol (Oxf). 1995; 43:55-68.

2. Liu M, Jing D, Hu J, Yin S. Predictive factors of outcomes in personalized radioactive iodine $\left({ }^{131} \mathrm{I}\right)$ treatment for Graves' disease. Am J Med Sci. 2014; 348:288-293. 
3. Solomon B, Glinoer D, Lagasse R, Wartofsky L. Current trends in the management of Graves' disease. J Clin Endocrinol Metab. 1990; 70:1518-1524.

4. Muldoon BT, Mai VQ, Burch HB. Management of Graves' disease: An overview and comparison of clinical practice guidelines with actual practice trends. Endocrinol Metab Clin North Am. 2014; 43:495-516.

5. Cruz Junior AF, Takahashi MH, Albino CC. Clinical treatment with anti-thyroid drugs or iodine-131 therapy to control the hyperthyroidism of Graves disease: A costeffectiveness analysis. Arq Bras Endocrinol Metabol. 2006; 50:1096-1101.

6. Hyer S, Kong A, Pratt B, Harmer C. Salivary gland toxicity after radioiodine therapy for thyroid cancer. Clin Oncol (R Coll Radiol). 2007; 19:83-86.

7. Hyer SL, Newbold K, Harmer CL. Early and late toxicity of radioiodine therapy: detection and management. Endocr Pract. 2010; 16:1064-1070.

8. Sioka C, Zouboulidis A, Fotopoulos A, Dimakopoulos $\mathrm{N}$. Re: risk of second primary malignancies in women with papillary thyroid cancer. Am J Epidemiol. 2007; 165:473; author reply 474.

9. Hyer S, Vini L, O'Connell M, Pratt B, Harmer C. Testicular dose and fertility in men following I(131) therapy for thyroid cancer. Clin Endocrinol (Oxf). 2002; 56:755-758.

10. Wichers M, Benz E, Palmedo H, Biersack HJ, Grunwald $\mathrm{F}$, Klingmuller D. Testicular function after radioiodine therapy for thyroid carcinoma. Eur J Nucl Med. 2000; 27:503-507.

11. Ceccarelli C, Bencivelli W, Morciano D, Pinchera A, Pacini F. ${ }^{131}$ I therapy for differentiated thyroid cancer leads to an earlier onset of menopause: Results of a retrospective study. J Clin Endocrinol Metab. 2001; 86:3512-3515.

12. Sioka C, Kouraklis G, Zafirakis A, Manetou A, Dimakopoulos N. Menstrual cycle disorders after therapy with iodine-131. Fertil Steril. 2006; 86: 625-628.

13. Franklyn JA, and Boelaert K. Thyrotoxicosis. Lancet. 2012; 379:1155-1166.

14. Georgiou HM, Di Quinzio MK, Permezel M, Brennecke SP. Predicting Preterm Labour: Current Status and Future Prospects. Dis Markers. 2015; 2015: 435014.

15. Yang M, Wang J, QIAN B, Dai J, Zhang X, Chen A, Meng Y. Monitoring and analysis of birth defects in 73498 infants. Journal of Clinical Pediatrics. 2015; 6:553-557. (in Chinese)

16. Zhang L, Liu KB, Pan Y, Zhang QL. Global progress in stillbirth study. Chinese Journal of Woman and Child Health Research. 2015; 26: 896-898. (in Chinese)

17. Dottorini ME, Lomuscio G, Mazzucchelli L, Vignati A, Colombo L. Assessment of female fertility and carcinogenesis after iodine-131 therapy for differentiated thyroid carcinoma. J Nucl Med. 1995; 36:21-27.

18. Sioka C, Fotopoulos A. Effects of I-131 therapy on gonads and pregnancy outcome in patients with thyroid cancer. Fertil Steril. 2011; 95:1552-1559.

19. Silberstein EB, Alavi A, Balon HR, Clarke SE, Divgi C, Gelfand MJ, Goldsmith SJ, Jadvar H, Marcus CS,
Martin WH, Parker JA, Royal HD, Sarkar SD, Stabin M, Waxman AD. The SNMMI practice guideline for therapy of thyroid disease with ${ }^{131}$ I 3.0. J Nucl Med. 2012; 53:1633-1651.

20. Hyer S, Pratt B, Newbold K, Hamer C. Outcome of pregnancy after exposure to radioiodine In utero. Endocr Pract. 2011; 1-10. doi: http://dx.doi.org/10.4158/EP10237. RA

21. American Thyroid Association Taskforce On Radioiodine S, Sisson JC, Freitas J, McDougall IR, Dauer LT, Hurley JR, Brierley JD, Edinboro CH, Rosenthal D, Thomas MJ, Wexler JA, Asamoah E, Avram AM, Milas M, Greenlee C. Radiation safety in the treatment of patients with thyroid diseases by radioiodine ${ }^{131} \mathrm{I}$ : Practice recommendations of the American Thyroid Association. Thyroid. 2011; 21:335-346.

22. Garsi JP, Schlumberger M, Rubino C, Ricard M, Labbe M, Ceccarelli C, Schvartz C, Henri-Amar M, Bardet $\mathrm{S}$, de Vathaire F. Therapeutic administration of ${ }^{131} \mathrm{I}$ for differentiated thyroid cancer: Radiation dose to ovaries and outcome of pregnancies. J Nucl Med. 2008; 49:845852.

23. do Rosário PW, Barroso AL, Rezende LL, Padrão EL, Borges MA, Purisch S. Malformations in the offspring of women with thyroid cancer treated with radioiodine for the ablation of thyroid remnants. Arq Bras Endocrinol Metabol. 2006; 50:930-933.

24. Balenovic A, Vlasic M, Sonicki Z, Bodor D, and Kusic Z. Pregnancy outcome after treatment with radioiodine for differentiated thyroid carcinoma. Coll Antropol. 2006; 30:743-748.

25. Bal C, Kumar A, Tripathi M, Chandrashekar N, Phom H, Murali NR, Chandra P, Pant GS. High-dose radioiodine treatment for differentiated thyroid carcinoma is not associated with change in female fertility or any genetic risk to the offspring. Int J Radiat Oncol Biol Phys. 2005; 63:449-455.

26. Brandao CD, Miranda AE, Correa ND, Sieiro Netto L, Corbo R, Vaisman M. Radioiodine therapy and subsequent pregnancy. Arq Bras Endocrinol Metabol. 2007; 51:534-540.

27. Fard-Esfahani A, Mirshekarpour H, Fallahi B, Eftekhari M, Saghari M, Beiki D, Ansari-Gilani K, Takavar A. The effect of high-dose radioiodine treatment on lacrimal gland function in patients with differentiated thyroid carcinoma. Clin Nucl Med. 2007; 32:696-699.

28. Vini L, Hyer S, Al-Saadi A, Pratt B, Harmer C. Prognosis for fertility and ovarian function after treatment with radioiodine for thyroid cancer. Postgrad Med J. 2002; 78:92-93.

29. Chow SM, Yau S, Lee SH, Leung WM, Law SC. Pregnancy outcome after diagnosis of differentiated thyroid carcinoma: No deleterious effect after radioactive iodine treatment. Int J Radiat Oncol Biol Phys. 2004; 59:992-1000.

(Received January 18, 2016; Revised February 22, 2016; Accepted April 27, 2016) 